\title{
Diallel Analysis of Quality and Yield Contributing Traits of Pumpkin (Cucurbita moschata Duch. ex Poir.)
}

\author{
M. S. Rana ${ }^{1}$, M. G. Rasul ${ }^{1}$, A. K. M. A. Islam ${ }^{1}$ and M. M. Hossain ${ }^{2}$ \\ ${ }^{1}$ Department of Genetics and Plant Breeding, ${ }^{2}$ Department of Horticulture, \\ Bangabandhu Sheikh Mujibur Rahman Agricultural University, Gazipur- 1706, Bangladesh \\ *Corresponding author and Email: sohel_rbd@yahoo.com
}

Received: 29 November 2015

Accepted: 12 June 2016

\begin{abstract}
A 5 X 5 diallel analysis was carried out according to Hayman on quality and yield contributing traits of pumpkin. Five (5) advanced inbreds of pumpkin viz IB 23, IB 40, IB 47, IB 50 and IB 57 were used in this study. The five parents and their $F_{1}$ hybrids were arranged in a randomized complete block design with three replications for studying the quality and yield contributing traits. Analysis of variance showed significant differences among genotypes for all of the traits except dry matter and fruit yield. Parental mean suggested that all the parents contained recessive alleles with positive effect. In the $5 \times 5$ diallel set, $W r$ - $V r$ graph analysis revealed the presence of allelic interaction in all the character's except fruit length, dry matter, brix percentage and reducing sugar where non-allelic interaction was present.
\end{abstract}

Keywords: Diallel, allelic interaction, non-allelic interaction, pumpkin

\section{Introduction}

Pumpkin is a very common crop, grown extensively throughout the tropical and subtropical countries. Due to its high nutritional content, it considered as a high value crop in Bangladesh. Pumpkins are rich in carbohydrates, minerals and a cheaper source of vitamins, especially carotenoid pigments (Bose and Som, 1986), which have a major role in the form of pro-vitamin A, when used at ripening stage (Dutta et al., 2006). It may be mentioned that until to date there is no released variety of pumpkin with high yield potential and better nutritional quality. Further, very limited attempt had been made for genetic improvement of this crop (Akter et al., 2013 Rana et al., 2015, Begum et al 2016). An understanding of the nature and magnitude of variability among the genetic stocks is of prime importance to the breeder. Diallel cross technique developed and illustrated by Hayman $(1954,1958)$ and Jink $(1954,1956)$ provide information on genetic mechanisms. Combining ability measured by diallel cross is one of the powerful tools in identifying the best combiners that may be used to exploit heterosis (Pandey et al, 2010) or to accumulate fixable genes (Srivastava and Bajpai, 1977, Hussein and Hamid, 2015). In order to formulate efficient breeding programs, for improvement of quality traits, it is essential to characterize the nature and mode of gene action that determines the yield and quality contributing components. The present studies were, therefore, conducted to ascertain the nature of gene action involved in controlling considered yield and quality contributing traits of pumpkin. 


\section{Materials and Methods}

The materials comprised of five advanced inbred lines viz., IB 23, IB 40, IB 47, IB 50 and IB 57 (designated as $\mathrm{P}_{1}, \mathrm{P}_{2}, \mathrm{P}_{3}, \mathrm{P}_{4}$ and $\mathrm{P}_{5}$, respectively) developed by the Department Genetics and Plant Breeding, BSMRAU was used in the study for combining ability analysis in a $5 \times 5$ diallel population. The inbreds were synthesized in the previous year. The 25 entries (20 crosses and five parents) were grown in a randomized complete block design with three replications at the experimental plot of Genetics and Plant Breeding Department, BSMRAU, Salna, Gazipur-1706 during November, 2012 to March, 2013 for studying performance. Observations were recorded and measured on fruit length, fruit breadth, hollowness, flesh thickness, dry matter percentage, brix percentage, reducing sugar, nonreducing sugar, total sugar and fruit yield. The traits indicating significant differences among genotypes were further analyzed for genetic studies and the gene action was determined by using Hayman (1954, 1958) and Jinks (1954, 1955, 1956) methods.

\section{Results and Discussion}

\subsection{Analysis of variance in Hayman's analysis (following Morley Jones)}

Analysis of variance showed that the significant values of ' $a$ ' for the character fruit length, hollowness, brix percentage, beta carotene, reducing sugar and non-reducing sugar suggested that additive components were involved in the regulation of these characters. The dominance component (b) was highly significant indicated that this component was important in genetic control of most of the characters studied except fruit length, dry matter, reducing sugar and fruit yield (Table 1). Item ' $b_{1}$ ' was highly significant for two character'sflesh thickness and beta carotene, which detected unidirectional dominance and significant difference between parental and hybrid grand mean for these two characters. An asymmetrical distribution of dominant genes was suggested by the significant ' $b_{2}$ ' value for the characters beta carotene, non-reducing sugar and total sugar.
The ' $b_{3}$ ' values were also significant for most of the character's studied except fruit length, dry matter, reducing sugar and fruit yield indicated the dominance deviations which are not attributable to ' $b_{1}$ ' and ' $b_{2}$ ' and showed important contribution to the non-additive gene action. Significant 'c' value for the trait fruit length, brix $(\%)$, beta carotene, reducing sugar and total sugar indicated the presence of maternal effect. Significant'd' value indicated presence of reciprocal difference in the character viz. fruit length, hollowness, brix (\%), reducing sugar and non-reducing sugar.

The analysis of variance due to diallel progenies indicated significant differences among themselves, which warrants further analysis. Hayman's graphic approach to diallel analysis is based on monogenic additive model. In this approach Hayman's graphical analysis ( $\mathrm{Vr}-\mathrm{Wr}$ graph) was done and the findings are presented as $\mathrm{Vr}-\mathrm{Wr}$ graphs, the two dimensional depiction made based on the parental variance $(\mathrm{Vr})$ and parent offspring co-variance $(\mathrm{Wr})$ are presented in the Fig. (1-11) for eleven characters studied.

\section{2. $V r-W r$ graphs and $W r+V r$ versus parental mean graph}

\subsubsection{Fruit length}

The regression of $\mathrm{Wr}$ on $\mathrm{Vr}$ for fruit length (Figure 1a) gave a slope $b=-0.394 \pm 0.356$ which was negative indicating presence of nonallelic interaction i.e. epistasis playing role for this trait. The distribution of array points indicated that among five parents $\mathrm{P}_{1}$ contained a frequency of dominant alleles and $\mathrm{P}_{3}$ possessing the maximum recessive alleles and other parents are intermediate between two. Array points scattered all along the regression line in this graph indicated genetic diversity among parents.

The $\mathrm{Wr}+\mathrm{Vr} /$ parental mean graph further confirmed the consistency of dominance against the parental score and the parental mean for this trait suggested that all the parents contained recessive alleles and most of the parents were high scoring (Figure 1b). So, parents having higher fruit length were consistently associated with recessive alleles in the direction of higher value. 
Table 1. Analysis of variance (ANOVA) in Hayman's analysis (following Morley Jones) for different traits in a five parental full diallel population of pumpkin

\begin{tabular}{|c|c|c|c|c|c|c|c|c|c|c|c|c|}
\hline \multirow{2}{*}{$\begin{array}{l}\text { Source of } \\
\text { Variation }\end{array}$} & \multirow{2}{*}{ df } & \multicolumn{11}{|c|}{ Mean sum of square } \\
\hline & & Fruit length & $\begin{array}{c}\text { Fruit } \\
\text { breadth }\end{array}$ & Hollowness & $\begin{array}{c}\text { Flesh } \\
\text { thickness }\end{array}$ & $\begin{array}{c}\text { Dry } \\
\text { matter }\end{array}$ & Brix & $\begin{array}{c}\text { Beta } \\
\text { carotene }\end{array}$ & $\begin{array}{l}\text { Reducin } \\
\text { g sugar }\end{array}$ & $\begin{array}{l}\text { Non } \\
\text { reducing } \\
\text { sugar }\end{array}$ & $\begin{array}{l}\text { Total } \\
\text { sugar }\end{array}$ & $\begin{array}{l}\text { Fruit } \\
\text { yield }\end{array}$ \\
\hline $\mathrm{a}$ & 4 & $8.35 * *$ & 1.57 & $1.696^{*}$ & 0.125 & 0.0128 & $1.04 *$ & $0.067 * *$ & $0.288 * *$ & $0.233^{*}$ & 0.185 & 1.55 \\
\hline $\mathrm{b}_{1}$ & 1 & 0.001 & 0.810 & 0.134 & $0.513^{* *}$ & 0.001 & 0.090 & $0.018 * *$ & 0.013 & 0.004 & 0.057 & 0.928 \\
\hline$b_{2}$ & 4 & 0.845 & 0.435 & 1.10 & 0.075 & 0.362 & 0.850 & $0.008 *$ & 0.063 & $0.246 * *$ & $0.241 * *$ & 3.15 \\
\hline$b_{3}$ & 5 & 0.701 & $3.95 * *$ & $2.12 *$ & $0.249 * *$ & 0.140 & $\begin{array}{c}2.19 * \\
*\end{array}$ & $0.008 * *$ & 0.119 & $0.373 * *$ & $0.624 * *$ & 0.694 \\
\hline $\mathrm{b}$ & 10 & 0.689 & $2.23 *$ & $1.51 *$ & $0.206^{* *}$ & 0.215 & $\begin{array}{c}1.44^{*} \\
*\end{array}$ & $0.009 * *$ & 0.086 & $0.285^{* *}$ & $0.414^{* *}$ & 1.70 \\
\hline $\mathrm{c}$ & 4 & $2.57 *$ & 1.07 & 1.12 & 0.094 & 0.204 & $\begin{array}{c}1.80 * \\
*\end{array}$ & $0.025 * *$ & $0.185^{*}$ & 0.135 & $0.336^{* *}$ & 1.39 \\
\hline $\mathrm{d}$ & 6 & $2.90 *$ & 0.853 & $1.49 *$ & 0.064 & 0.071 & $\begin{array}{c}1.10^{*} \\
*\end{array}$ & 0.004 & $0.169^{*}$ & $0.184 * *$ & 0.126 & 0.398 \\
\hline Error & 48 & 0.919 & 0.812 & 0.634 & 0.061 & 0.162 & 0.379 & 0.002 & 0.062 & 0.059 & 0.082 & 1.28 \\
\hline
\end{tabular}

* Indicates significant in 5\% level of significance, where ** Indicates significant in $1 \%$ level 
a
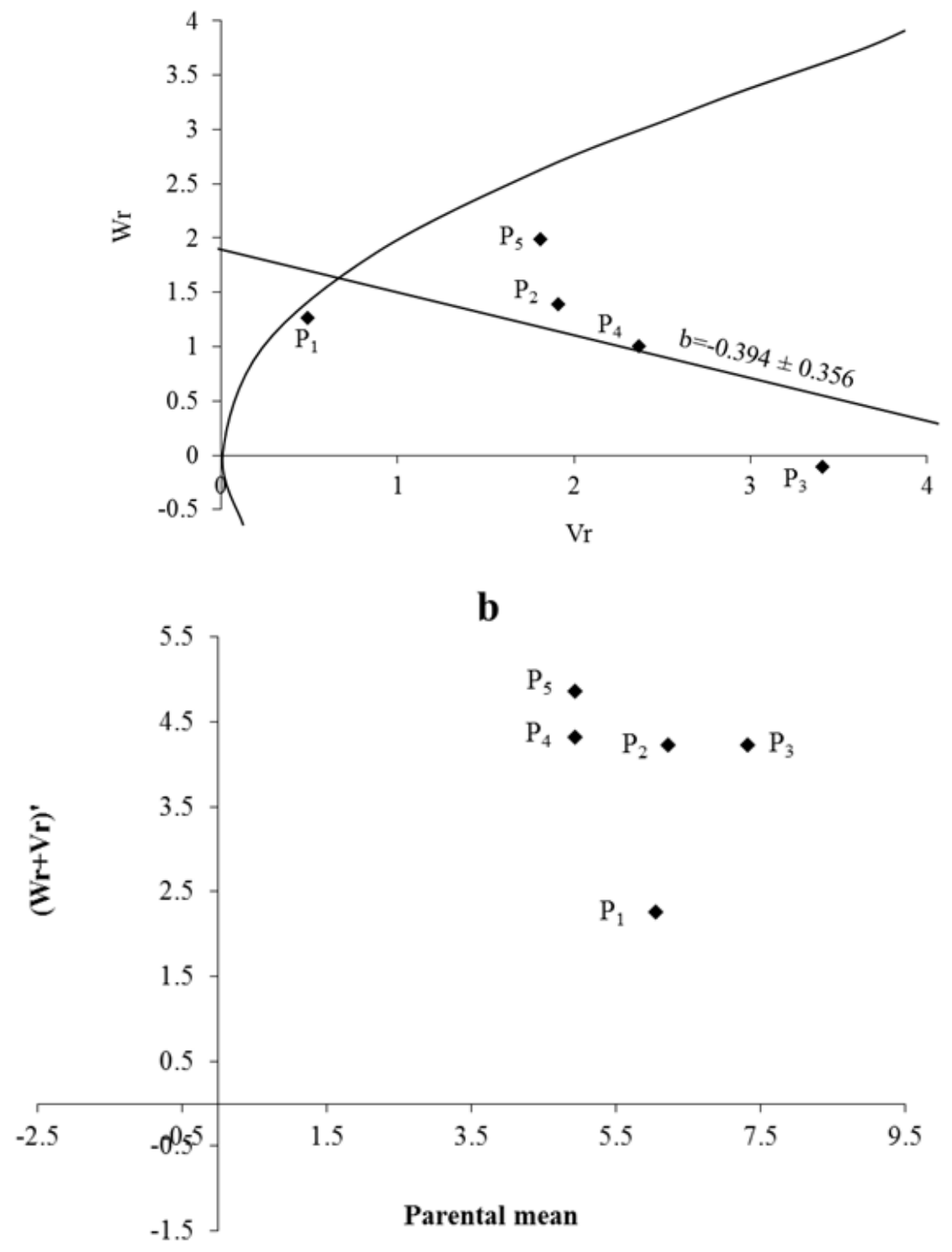

Figure 1. $\mathrm{Vr}$ - Wr graphs (a) and $\mathrm{Wr}+\mathrm{Vr} /$ parental mean graph (b) for fruit length 


\subsubsection{Fruit breadth}

The Vr - Wr graph (Figure 2a) for fruit breadth showed that the regression line intersected above the point of origin which indicated the presence of partial dominance for fruit breadth. The distribution of array points in the graph suggested that the parental genotypes $\mathrm{P}_{1}, \mathrm{P}_{4}$ and $\mathrm{P}_{3}$ apparently contained higher frequency of dominant alleles while $\mathrm{P}_{2}$ had the most recessive alleles as it fell far away to the point of origin. Array points scattered all along the regression line in this graph indicated genetic diversity among parents. The regression of $\mathrm{Wr}$ on $\mathrm{Vr}$ gave the slope $b=0.118 \pm 0.311$ which was less than 1 , affirming presence of additive-additive nature of genetic system.

It was observed from the $\mathrm{Wr}+\mathrm{Vr} /$ parental mean graph (Figure 2b) that all the parents possess recessive alleles associated with positive effect which would result increased fruit breadth. Contrarily, dominant alleles will have negative effect.

\subsubsection{Hollowness}

The regression of $\mathrm{Wr}$ on $\mathrm{Vr}$ for hollowness (Figure 3a) gave a slope $b=0.284 \pm 0.318$ which was less than 1.0 indicating presence of additiveadditive nature of genetic system. The regression line intersected below the point of origin suggesting over dominance gene action for controlling the trait. The distribution of array points indicated that parents $\mathrm{P}_{1}$ and $\mathrm{P}_{4}$ contained the maximum frequency of dominant alleles while the maximum recessive alleles was found in $\mathrm{P}_{2}$ as it fell far away to the point of origin. Dispersed array points all along the regression line in this graph indicated genetic diversity among parents.

It was observed from the $\mathrm{Wr}+\mathrm{Vr}$ versus parental mean graph (Figure 3b) that all the parents contained the recessive alleles with positive effects. Contrarily, dominant alleles had negative effect that will increase hollowness of fruit. Pandey et al (2010) found the similar results.

\subsubsection{Flesh thickness}

The regression of $\mathrm{Wr}$ on $\mathrm{Vr}$ for flesh thickness (Figure $4 a$ ) gave a slope $b=0.549 \pm 0.473$ which close to 1.0 indicating presence of additivedominance nature of genetic system. The regression line intersected below the point of origin suggested over dominance gene action for controlling the trait. The distribution of array points indicated that among five parents, $\mathrm{P}_{2}$ contained the maximum frequency of dominant alleles as it held closest position to the point of origin. The parent $\mathrm{P}_{4}$ contained the maximum frequency of recessive alleles. Array points sprinkled all along the regression line in this graph indicated genetic diversity among parents. The $\mathrm{Wr}+\mathrm{Vr}$ /parental mean graph (Figure $4 \mathrm{~b}$ ) test the consistency of dominance against parental score. Parental mean suggested that all the parents contained the recessive alleles. Among them $\mathrm{P}_{4}$ had the highest value as it held on the top most position, all other had moderate score. So, higher flesh thickness was associated with recessive alleles in the direction of higher values. Pandey et al (2010) observed the similar results for this trait.

\subsubsection{Dry matter (\%)}

The Vr - Wr graph (Figure 5a) for dry matter showed that the regression line intersected above the point of origin which indicated the presence of partial dominance for dry matter percentage. The distribution of array points in the graph suggested that the parent $\mathrm{P}_{4}$ occupying the closest position to the origin possessed the maximum frequency of dominant alleles and the parent $\mathrm{P}_{1}$ contained the maximum frequency of recessive alleles. Array points sprinkled all along the regression line in this graph indicated genetic diversity among parents. The regression of $\mathrm{Wr}$ on $\mathrm{Vr}$ gave the slope $\mathrm{b}=-0.356 \pm 0.430$ which was negative affirming presence of non-allelic interaction i.e. epistasis playing role for this trait. The $\mathrm{Wr}+\mathrm{Vr}$ versus parental mean graph (Figure $5 b)$ test the consistency of dominance against parental score. Parental mean suggested that all the parents contained recessive alleles. The 
parent $\mathrm{P}_{2}$ possessed recessive alleles were high scoring whereas parents $\mathrm{P}_{4}$ with recessive alleles were low scoring for this trait. High dry matter content was therefore associated with parents having recessive alleles. Rana et al (2015) had the similar view on this trait.

$\mathbf{a}$

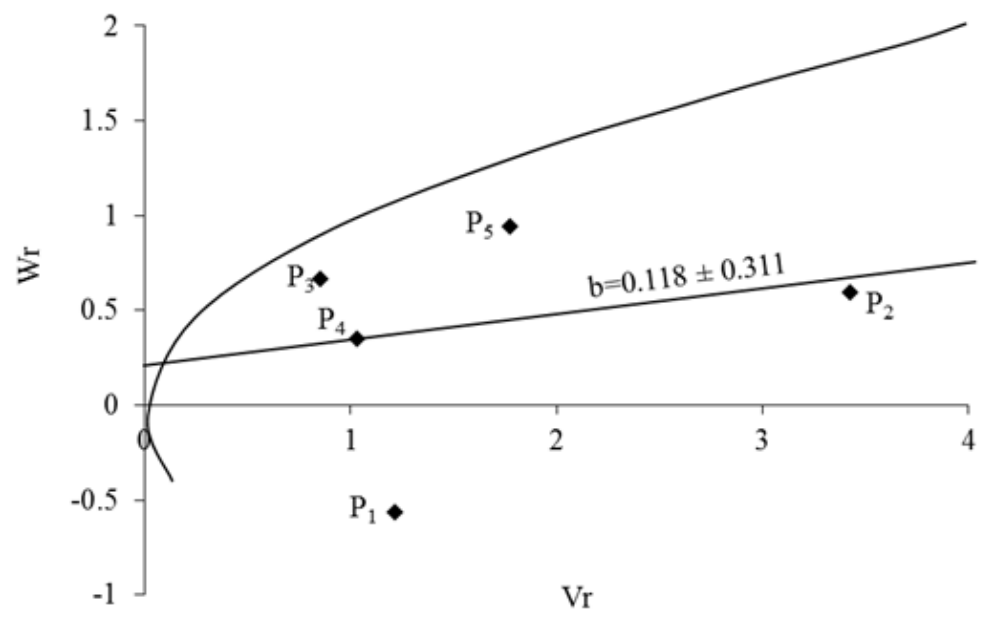

b

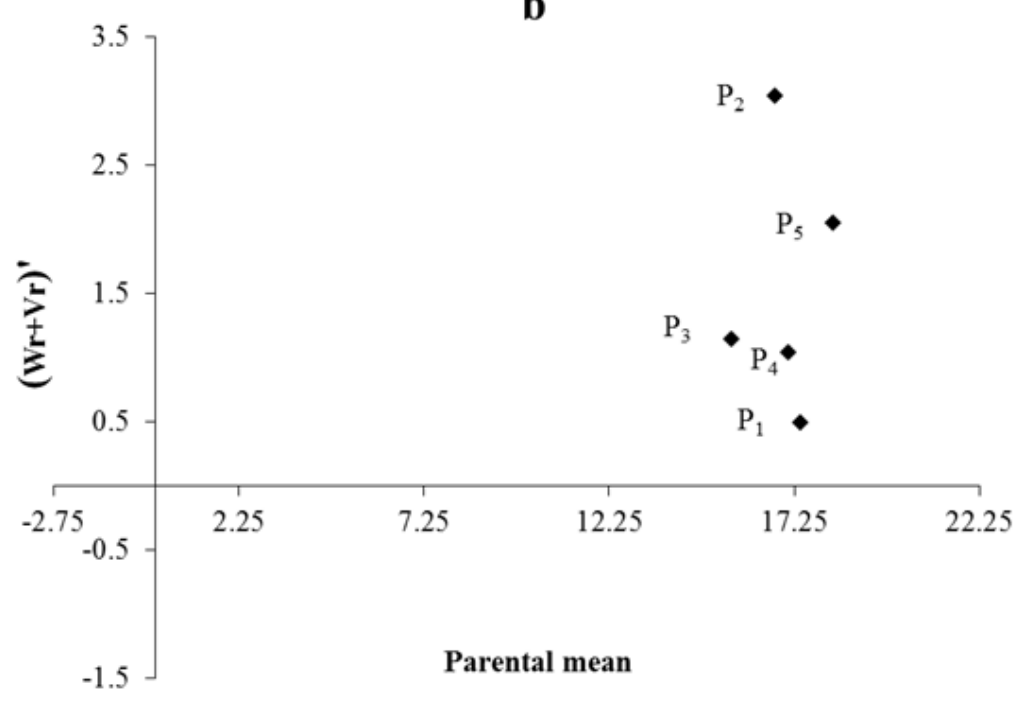

Figure 2. $\mathrm{Vr}-\mathrm{Wr}$ graphs (a) and $\mathrm{Wr}+\mathrm{Vr} /$ parental mean graph (b) for fruit breadth 
a

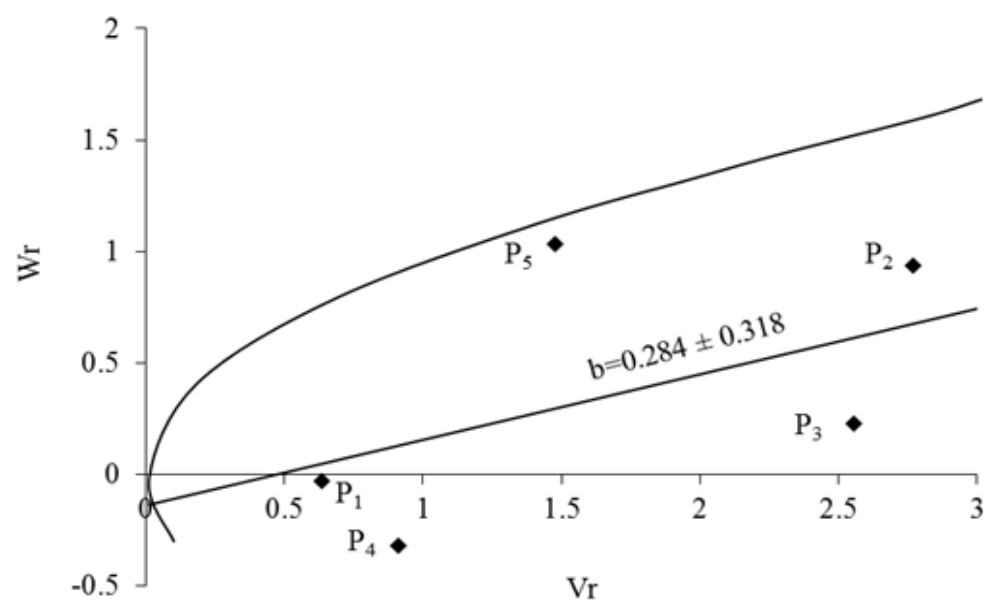

b

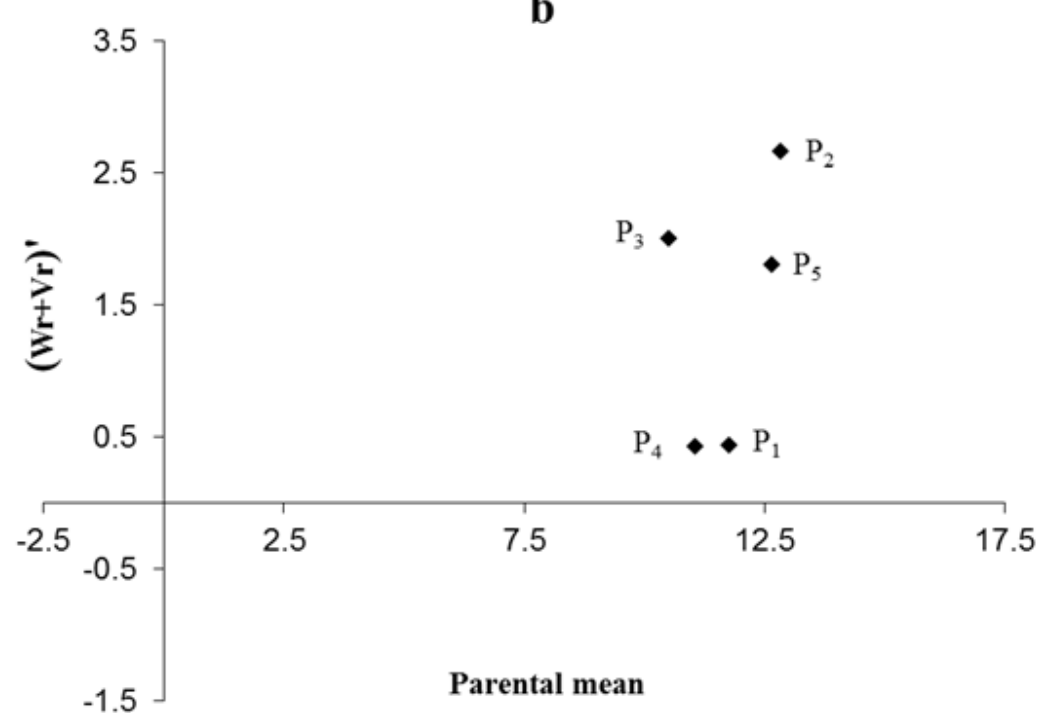

Figure 3. $\mathrm{Vr}-\mathrm{Wr}$ graphs (a) and $\mathrm{Wr}+\mathrm{Vr} /$ parental mean graph (b) for hollowness 
a

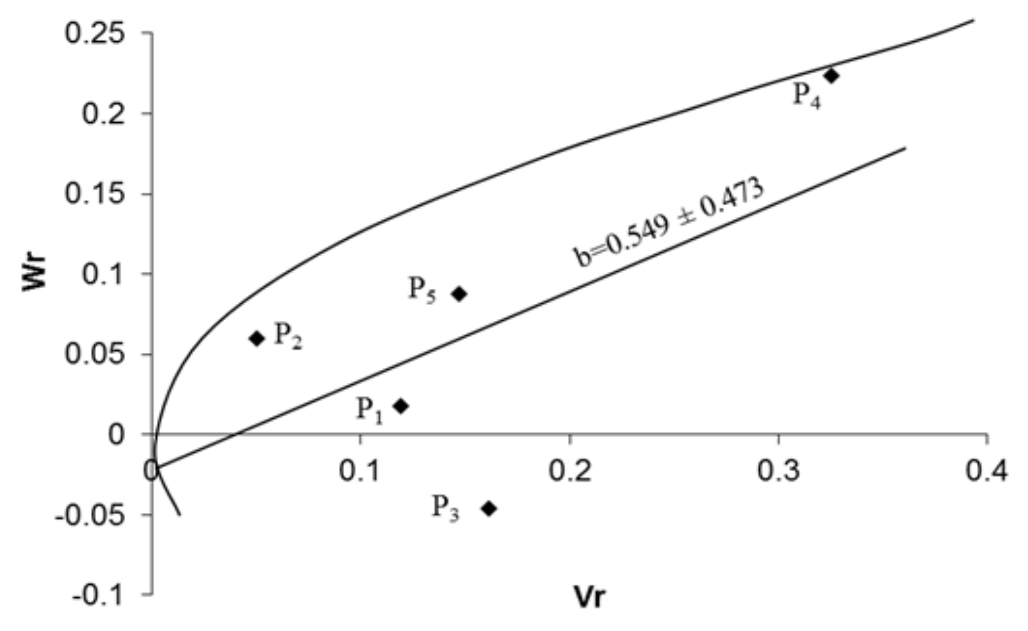

b

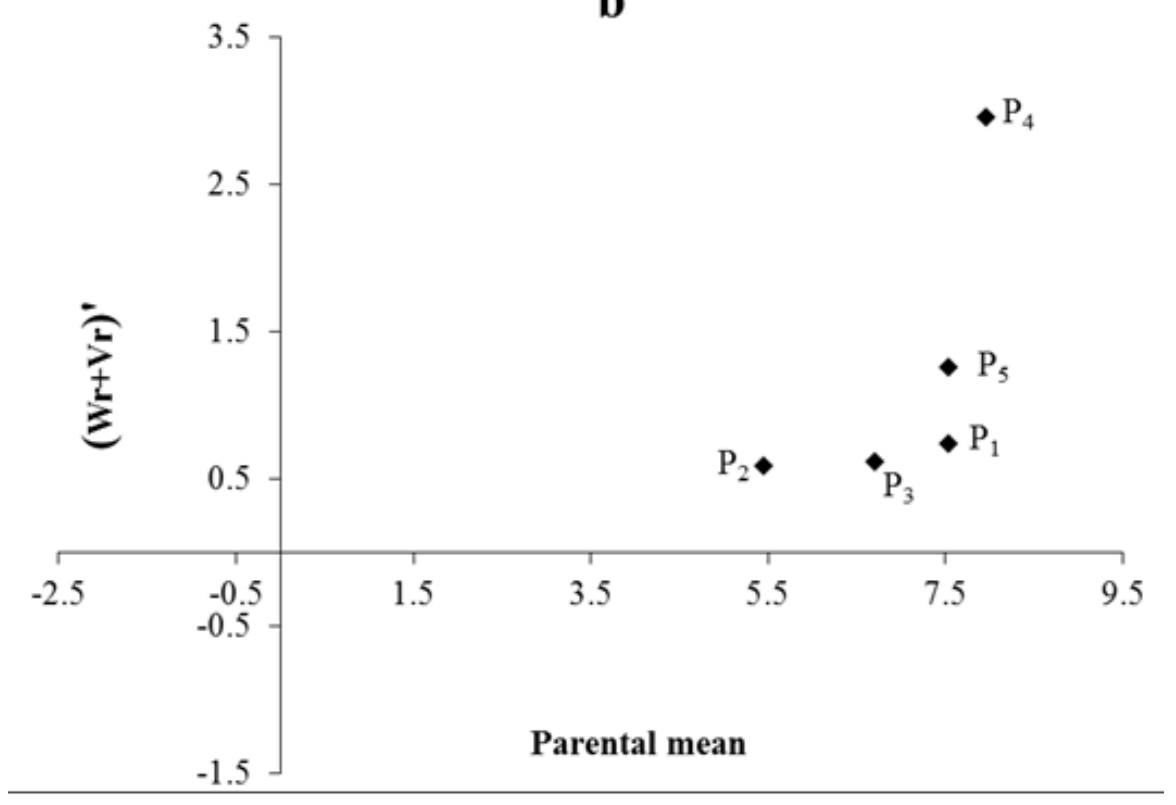

Figure 4. $\mathrm{Vr}-\mathrm{Wr}$ graphs (a) and $\mathrm{Wr}+\mathrm{Vr} /$ parental mean graph (b) for flesh thickness 
a
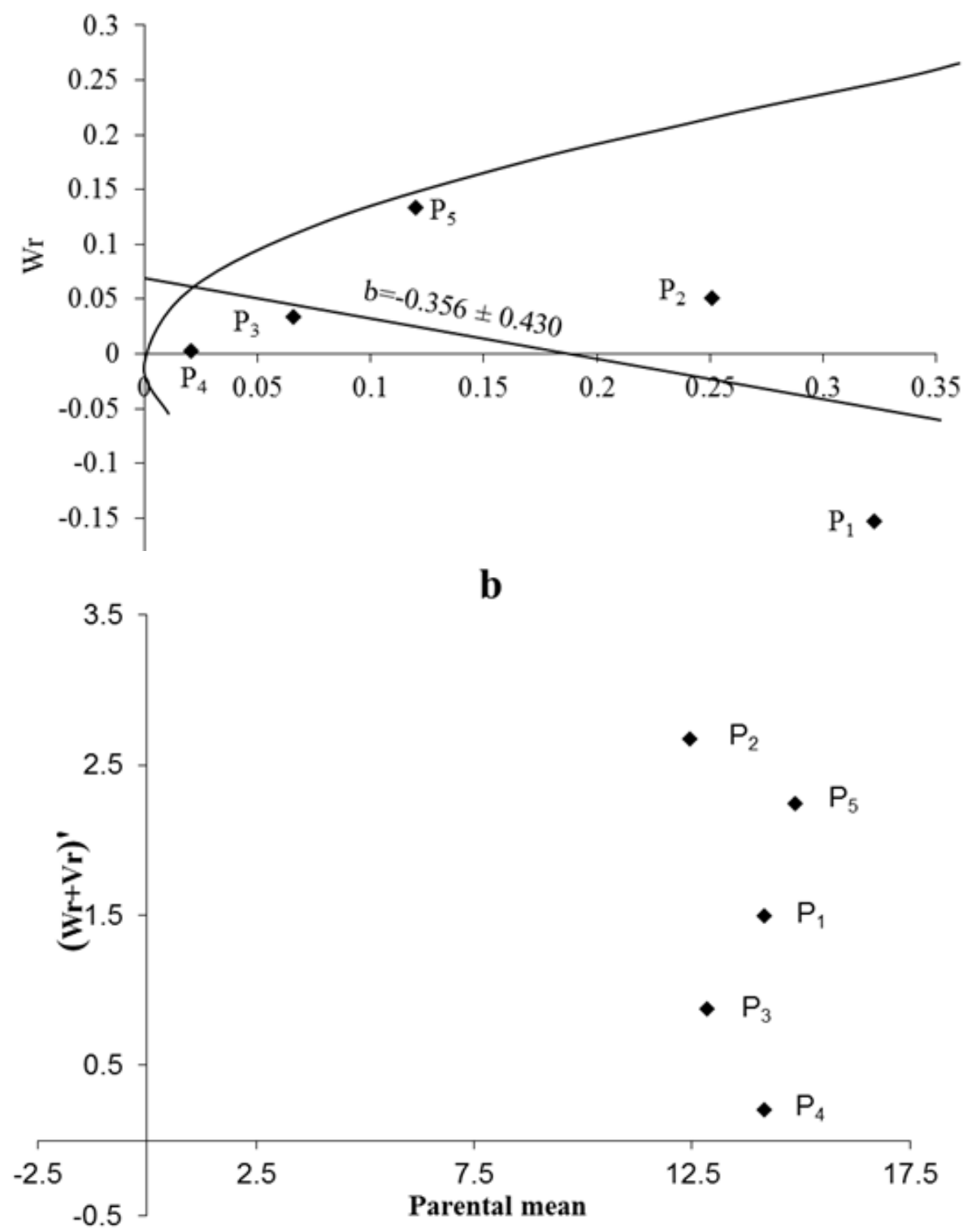

Figure 5. $\mathrm{Vr}-\mathrm{Wr}$ graphs (a) and $\mathrm{Wr}+\mathrm{Vr} /$ parental mean graph (b) for dry matter percent 


\subsubsection{Brix percentage}

The Vr - Wr graph (Figure 6a) for brix percentage showed that the regression line intersected above the point of origin which indicated the presence of partial dominance for brix (\%). The distribution of array points in the graph suggested that the parental genotypes $\mathrm{P}_{1}$ and $\mathrm{P}_{5}$ apparently contained the large number of dominant alleles, while $\mathrm{P}_{4}$ had the most recessive alleles. Dispersed array points all along the regression line in this graph indicated genetic diversity among parents. The regression of $\mathrm{Wr}$ on $\mathrm{Vr}$ gives the slope $\mathrm{b}=-0.038 \pm 0.286$ which was negative affirming presence of non-allelic interaction i.e. epistasis playing role for this trait. The $\mathrm{Wr}+\mathrm{Vr}$ versus parental mean graph (Figure 6b) affirmed that the brix (\%) was conditioned by recessive alleles were high scoring for the parent $\mathrm{P}_{4}$ while parent $\mathrm{P}_{5}$ had lowest score. All the parental values were positive revealed that predominance of alleles producing positive effects. Therefore, parents having high brix (\%) were consistently associated with recessive alleles in the direction of higher value. Tamilselvi et al (2012) observed the similar results for this trait.

\subsubsection{Beta carotene}

The regression of $\mathrm{Wr}$ on $\mathrm{Vr}$ for beta carotene (Figure 7a) gave a slope $\mathrm{b}=0.988 \pm 0.526$ which was close to 1.0 indicating presence of additivedominance nature of genetic system. The regression line intersected the point of origin suggesting complete dominance gene action for controlling the trait. The distribution of array points indicated that out of five parents, $\mathrm{P}_{2}$ and $\mathrm{P}_{4}$ contained the maximum frequency of dominant alleles as they fell near to the point of origin. Dispersed array points all along the regression line in this graph indicated genetic diversity among parents.

The $\mathrm{Wr}+\mathrm{Vr} /$ parental mean graph (Figure 7b) confirmed that the parents contained the most recessive alleles and parental values were positive revealed that predominance of alleles producing positive effects. Therefore, $\mathrm{P}_{1}, \mathrm{P}_{3}$ and
$\mathrm{P}_{5}$ possessed recessive alleles associated with positive effect i.e. increased $\beta$ carotene. Contrarily, dominant alleles had negative effect that would reduce $\beta$ carotene content. Tamilselvi et al (2012) observed the similar results for this trait.

\subsubsection{Reducing sugar}

The $\mathrm{Vr}$ - Wr graph (Figure 8a) for reducing sugar showed that the regression line passed above the point of origin which indicated the presence of partial dominance for reducing sugar. The distribution of array points in the graph suggested that $\mathrm{P}_{3}$ had the maximum frequency of dominant alleles, $\mathrm{P}_{4}$ and $\mathrm{P}_{2}$ showed equal frequency of dominant and recessive while $\mathrm{P}_{5}$ had the maximum frequency of recessive alleles as it fell far away from the origin. The regression of $\mathrm{Wr}$ on $\mathrm{Vr}$ gave the slope $\mathrm{b}=$ $0.168 \pm 0.649$ which was less than 1 , affirming presence of additive-additive nature of genetic system. Diffused array points all along the regression line in this graph indicated genetic diversity among parents. The $\mathrm{Wr}+\mathrm{Vr} /$ parental mean graph (Figure $8 \mathrm{~b}$ ) revealed that all of the parents contained the recessive alleles with positive effect. The parent $\mathrm{P}_{1}$ were scoring high while $\mathrm{P}_{3}$ was low and other parents were moderate.

\subsubsection{Non reducing sugar}

The regression of $\mathrm{Wr}$ on $\mathrm{Vr}$ for non-reducing sugar (Figure 9a) gave a slope $b=-0.204 \pm 0.343$ which was negative affirming presence of nonallelic interaction i.e. epistasis playing role for non-reducing sugar. The regression line intersected above the point of origin suggesting partial dominance gene action for controlling this trait. The distribution of array points indicated that among five parents, $\mathrm{P}_{4}$ contained the maximum frequency of dominant alleles. Equal frequency of dominant and recessive alleles was assured in $\mathrm{P}_{2}$ and $\mathrm{P}_{5}$ as it occupied intermediate position. Diffused array points all along the regression line in this graph indicated genetic diversity among parents. The $\mathrm{Wr}+\mathrm{Vr} /$ parental 
mean graph (Figure 9b) test the consistency of dominance against parental score. Parental mean suggested that all the parents contained recessive alleles with positive effect. The parent $\mathrm{P}_{5}$ and $\mathrm{P}_{4}$ had the highest and lowest frequency of recessive alleles, respectively.

$\mathbf{a}$

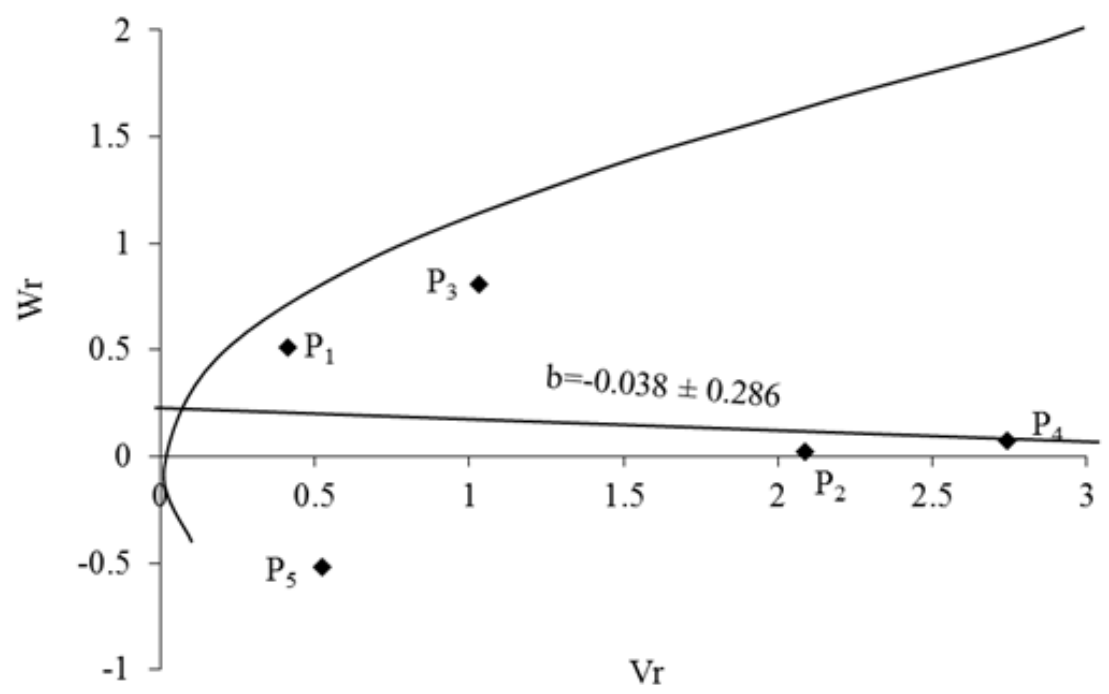

b

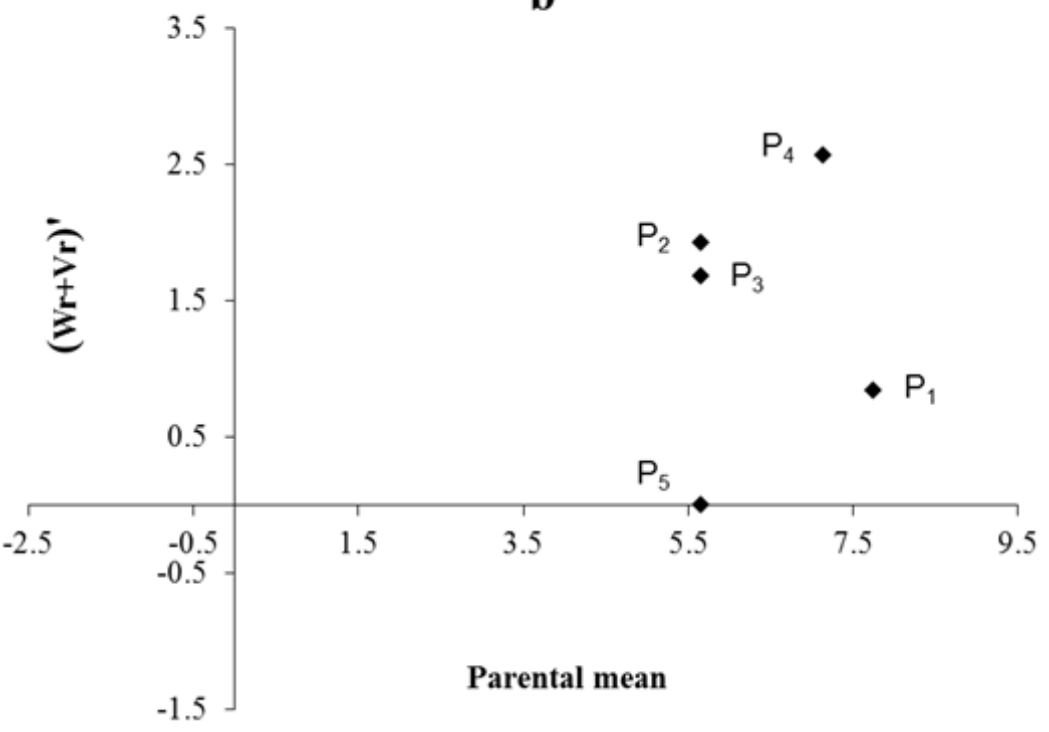

Figure 6. $\mathrm{Vr}$ - Wr graphs (a) and $\mathrm{Wr}+\mathrm{Vr} /$ parental mean graph (b) for brix (\%) 

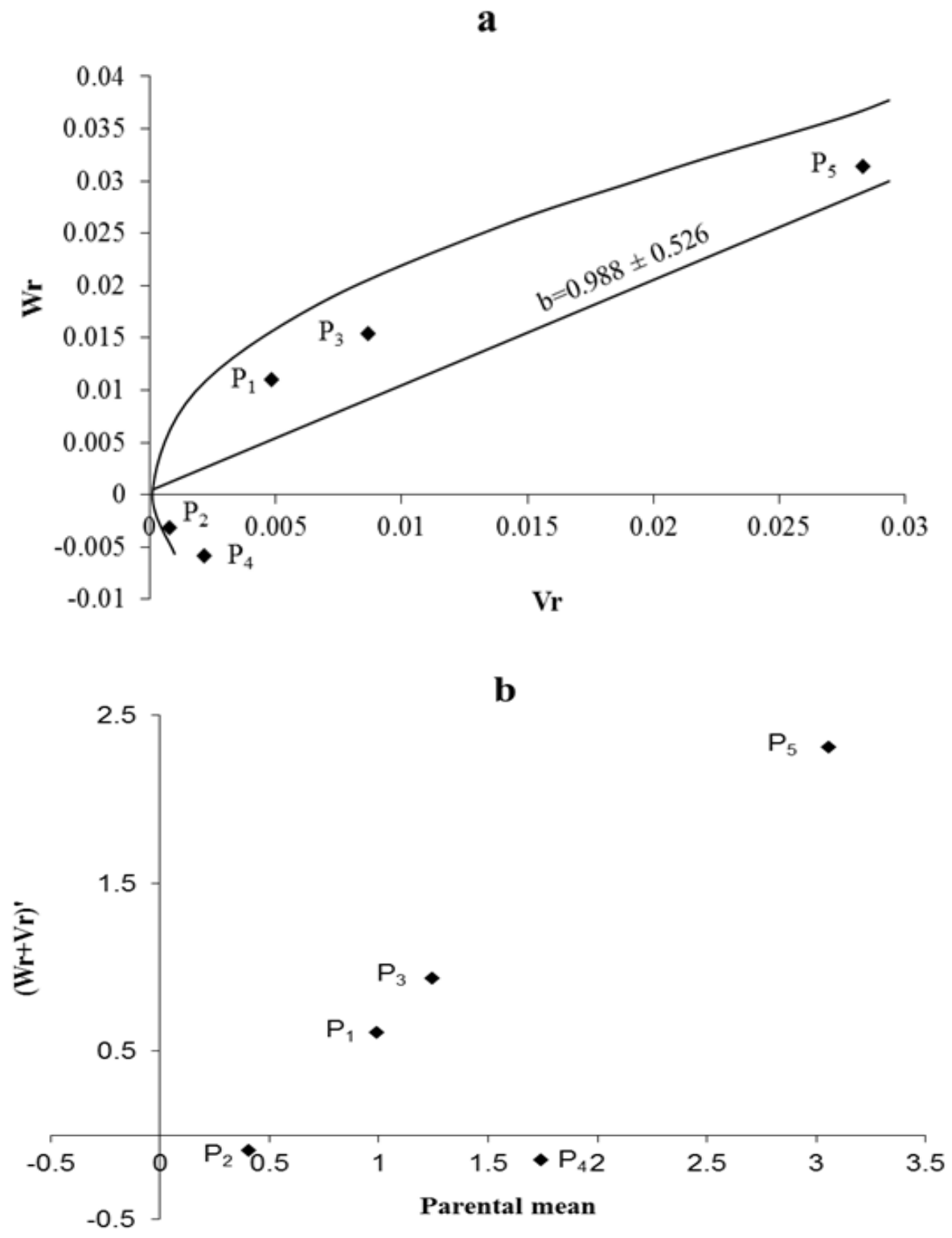

Figure 7. $\mathrm{Vr}$ - Wr graphs (a) and $\mathrm{Wr}+\mathrm{Vr} /$ parental mean graph (b) for beta carotene 
a
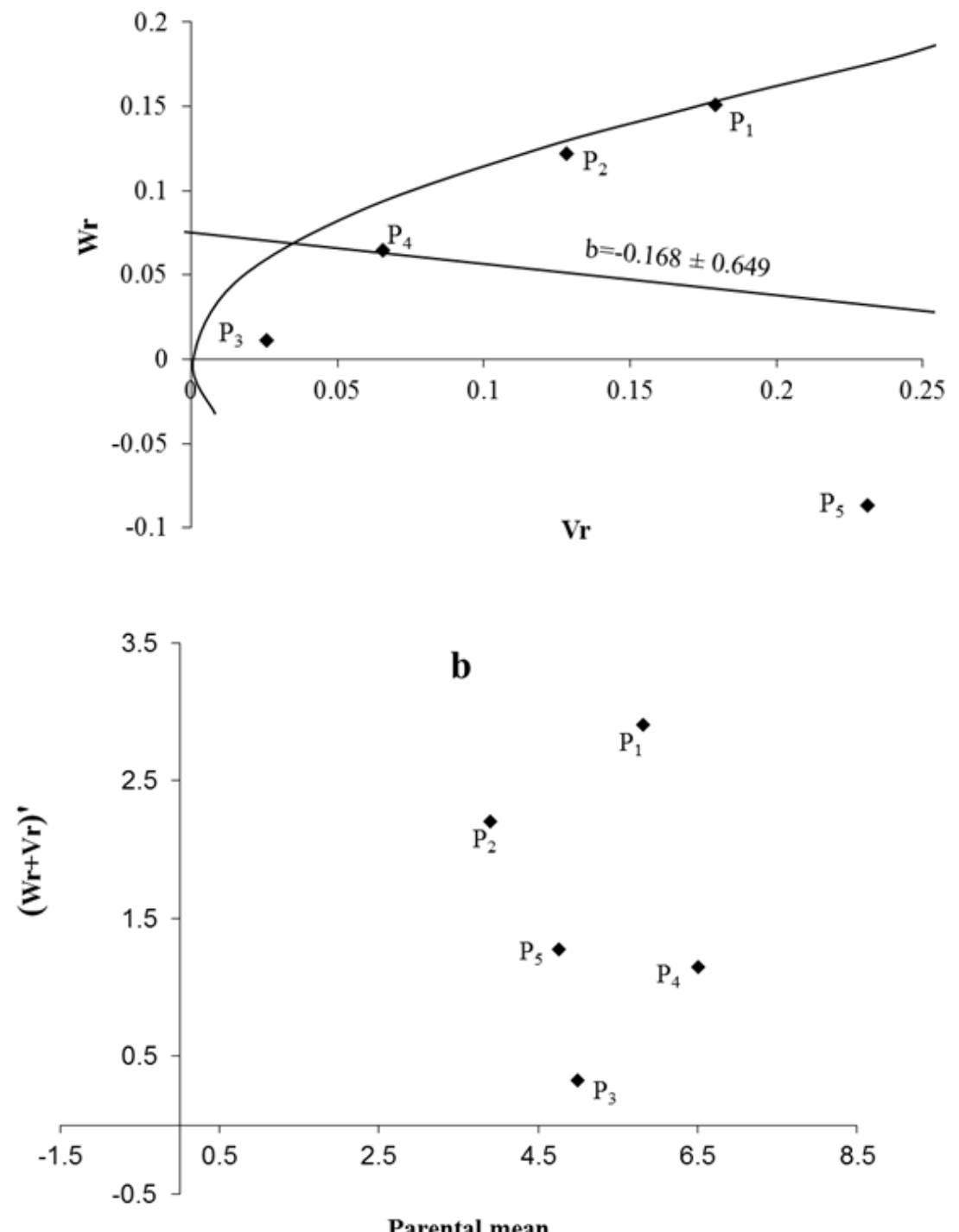

Figure 8. $\mathrm{Vr}$ - Wr graphs (a) and $\mathrm{Wr}+\mathrm{Vr}$ /parental mean graph (b) for reducing sugar 

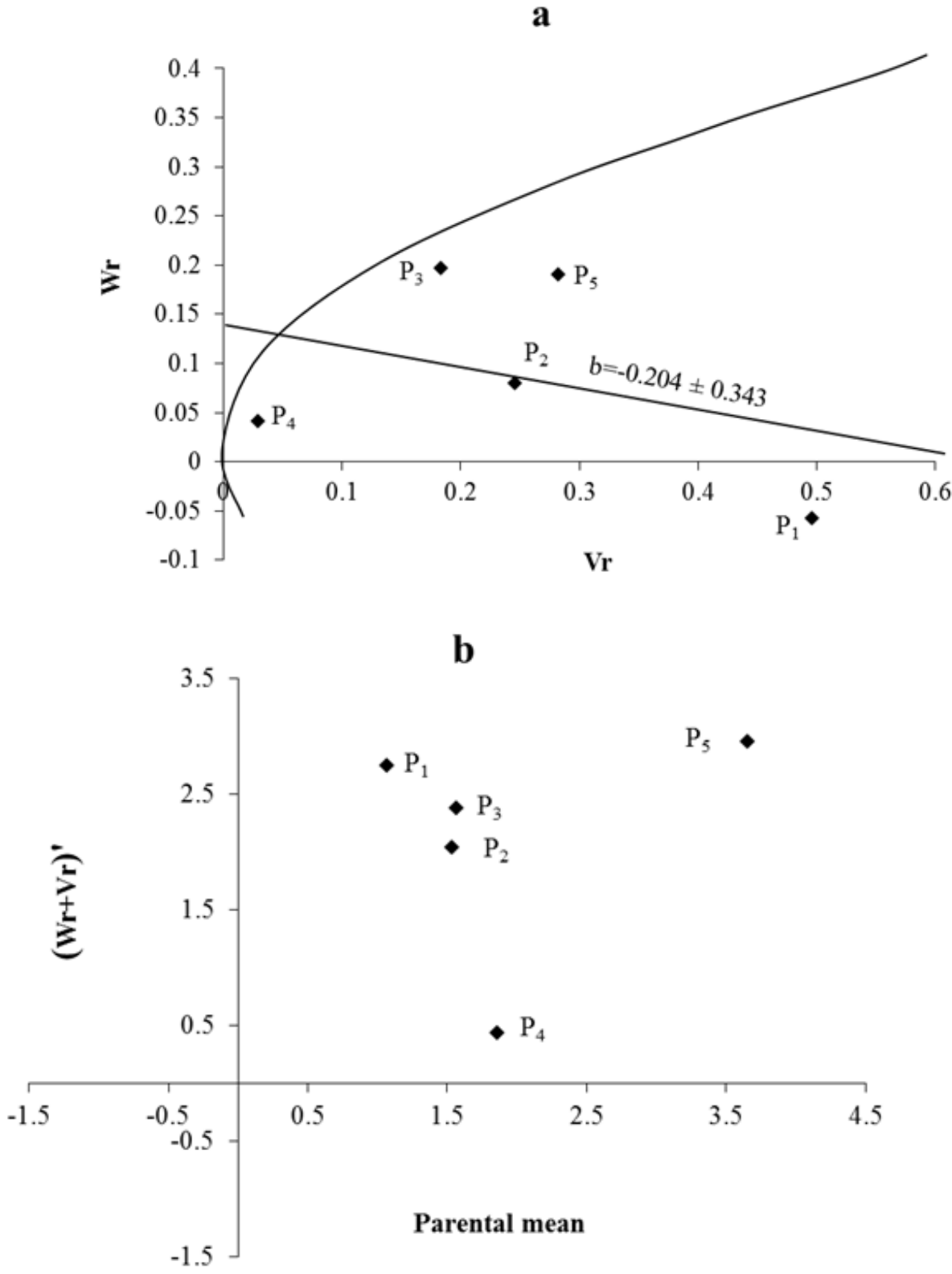

Figure 9. Vr - Wr graphs (a) and $\mathrm{Wr}+\mathrm{Vr}$ /parental mean graph (b) for non-reducing sugar 
a
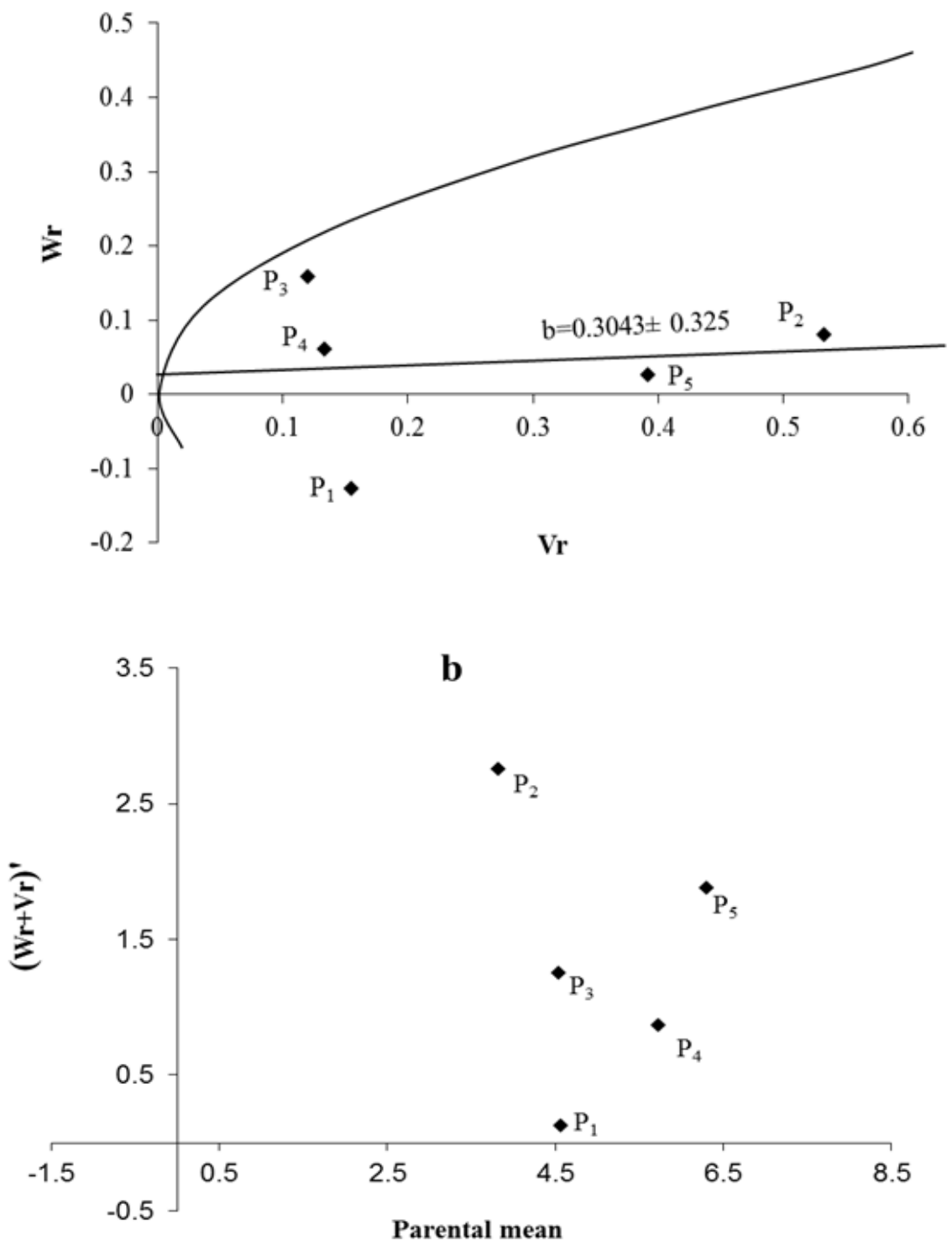

Figure 10. $\mathrm{Vr}$ - Wr graphs (a) and $\mathrm{Wr}+\mathrm{Vr} /$ parental mean graph (b) for total sugar 
a
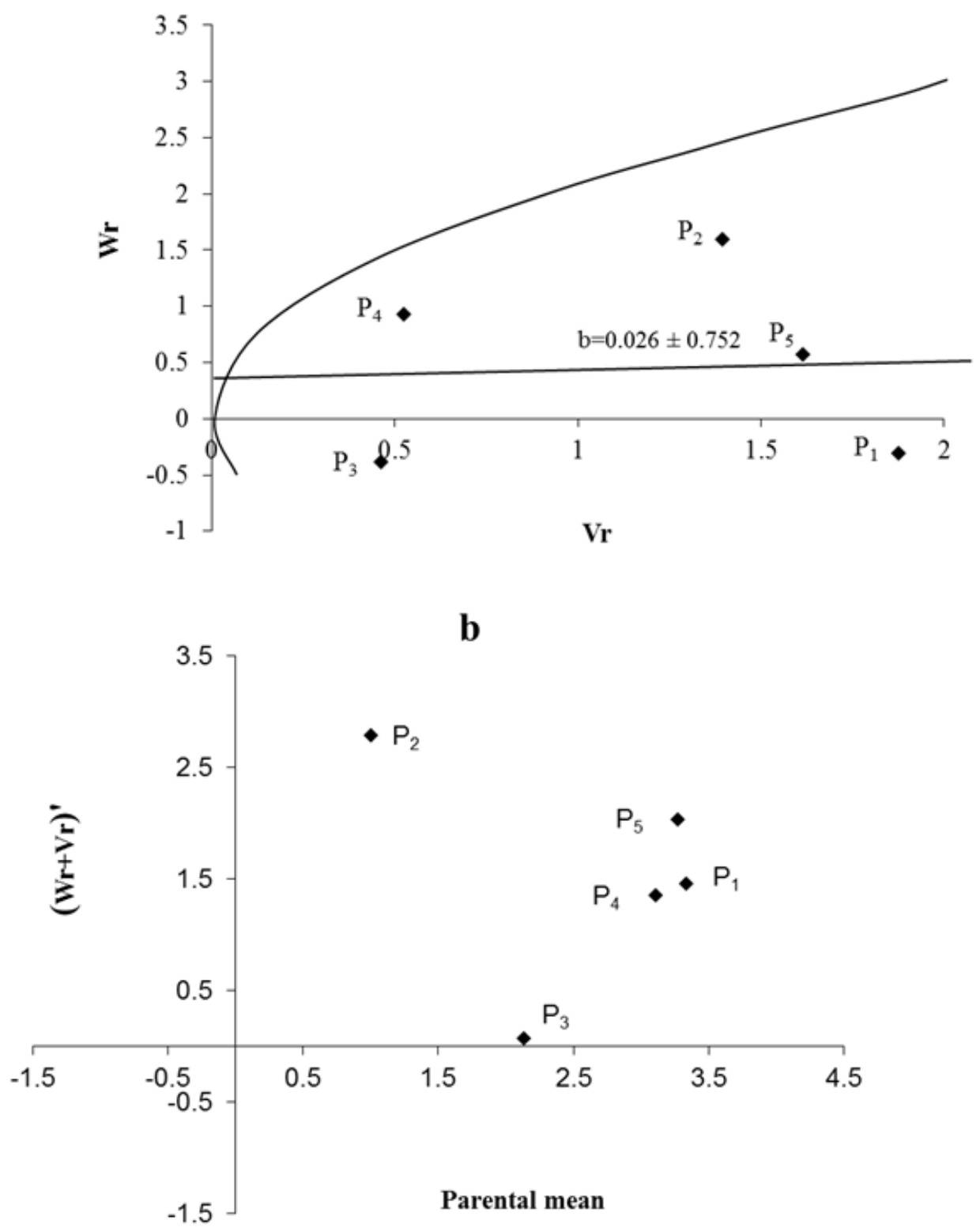

Figure 11. $\mathrm{Vr}-\mathrm{Wr}$ graphs (a) and $\mathrm{Wr}+\mathrm{Vr} /$ parental mean graph (b) for fruit yield 


\subsubsection{Total sugar}

The regression of $\mathrm{Wr}$ on $\mathrm{Vr}$ for total sugar (Figure 10a) gave a slope $b=0.304 \pm 0.325$ which was less than 1.0 indicating presence of additive-additive nature of genetic system. The regression line intersected above the point of origin suggesting partial dominance gene action for controlling the trait. The distribution of array points indicated that among five parents, $\mathrm{P}_{1}, \mathrm{P}_{3}$ and $\mathrm{P}_{4}$ contained the maximum frequency of dominant alleles. $\mathrm{P}_{2}$ had the maximum frequency of recessive alleles as it fell far away to the point of origin. Array points sprinkled all along the regression line in this graph indicated genetic diversity among parents. Rana et al (2015) had similar report in their experiment.

The $\mathrm{Wr}+\mathrm{Vr} /$ parental mean graph (Figure 10b) test the consistency of dominance against parental score. All the five parent possessed recessive alleles associated with positive effect for total sugar content.

\subsubsection{Fruit yield}

The Vr - Wr graph (Figure 11a) for fruit yield showed that the regression line intersected above the point of origin which indicated the presence of partial dominance for fruit yield. The distribution of array points in the graph suggested that the parent $\mathrm{P}_{3}$ contained a frequency of dominant alleles and all other parents contained a frequency of recessive alleles. The regression of $\mathrm{Wr}$ on $\mathrm{Vr}$ yielded the slope $b=0.026 \pm 0.752$ which was less than 1 , affirming additive-additive nature of genetic system. The $\mathrm{Wr}+\mathrm{Vr}$ versus parental mean graph confirmed that all the five parents possess recessive alleles associated with positive effect i.e. high fruit yield (Figure 11b). Moualla et al (2011) also made similar observation in pumpkin.

\section{Conclusions}

Diallel analysis was done to find out promising parents for further use in a breeding program to develop a new variety with more nutritional quality and higher yield. In this experiment, no parent was found promising for more than three traits, even the parents were not containing any dominant alleles. So further advancement i.e. selfing of selected line is needed to ensure more frequency of dominant alleles as well as resulting in good combination for several quality and yield contributing character.

\section{References}

Akter, S., Rasul, M. G., Aminul Islam, A. K. M. and Hossain, M. M. 2013. Genetic variability, correlation and path coefficient analysis of yield and quality traits in pumpkin (Cucurbita moschata Duch ex Poir.). Bangladesh Journal of Plant Breeding and Genetics. 26(1): 2533.

Begum, F., Akanda, A. M., Masud, M. A. T., Rasul, M. G. and Islam, M. A. 2016. Combining ability and heterosis analysis for PRSV-W resistance in pumpkin (Cucurbita moschata). Journal of International Academic Research for Multidisciplinary. 4(1):92-102. www.jiarm.com

Bose, T. K. and Som, M. G. 1998. Vegetables Crops in India, NayaProkash, Calcutta, 92-95 pp.

Dutta, D., Chaudhuri, U. R. and Chakraborty. R. 2006. Effect of thermal treatment on the P-carotene content, colour and textural properties of pumpkin. Journal of Food Science and Technology. 43 (6): 607-611.

Hayman, B.I. 1954. The theory and analysis of diallel crosses. Genetics, 39: 789-809.

Hayman, B.I. 1958. The theory and analysis of diallel cross. II. Genetics, 43: 63-85.

Hussien, A. H. and Hamed. A. A. 2015. Diallel analysis for studying heterosis and combining ability of some economical yield traits in pumpkin. Journal of Plant Production, Mansoura University. 6 (3): $261-270$. 
Jinks, J. L. 1954. The analysis of continuous variation in diallel crosses of Nicoliana rustica varieties. Genetics, 39: 767788.

Jinks, J. L. 1955. A survey of genetical basis of heterosis in a variety of diallel crosses. Heredity, 9: 233.

Jinks, J. L. 1956. The $\mathrm{F}_{2}$ and backcross generation from a set of diallel crosses. Heredity, 10: 1-30

Mohanty, B. K. and Mishra, R. S. 2000. Studies on combining ability for flowering traits in pumpkin. Haryana Journal of Horticultural Sciences. 29(3/4):220-222.

Mohanty, B. 2000. Combining ability for yield and its components in pumpkin. The Indian Journal of Genetics and Plant Breeding. 60(3): 373-379.

Morley-Jones, R. 1965. The analysis of variance of the half diallel table. Heredity. 20: 117121.
Moualla, M.Y., Boras, M. G and Marie, A. K. 2011. Studying the Genetic Behavior of Squash Yield and its Components Cucurbita pepo L. Tishreen University Journal for Research and Scientific Studies - Biological Sciences Series. 33 (1): 111-126.

Pandey, S., Jha, A., Kumar, S. and Rai, M. 2010. Genetics and heterosis of quality and yield of pumpkin. Indian Journal of Horticulture. 67(3): 333-338

Rana, M S, Rasul, M. G., Aminul Islam, A. K. M. and Hossain. M M. 2015. Combining ability of quality traits in pumpkin (Cucurbita moschata Duch. ex Poir.). Bangladesh Research Publications Journal, 11(3): 233-236.

Tamilselvi, N. A., Jansirani, P. and Pugalendhi, L. 2015. Estimation of heterosis and combining ability for earliness and yield characters in pumpkin (Cucurbita moschata Duch. Ex. Poir). African Journal of Agricultural Research. 10(6): 1904-1912. 